\title{
Arachnoid cysts of the left temporal fossa: impaired preoperative cognition and postoperative improvement
}

\author{
Knut Wester, Kenneth Hugdahl
}

\begin{abstract}
Thirteen adult patients were operated on for symptomatic arachnoid cysts in the left temporal fossa; seven with an internal shunt procedure during local anaesthesia, and five with a craniotomy with fenestration of the cyst to the basal cisterns. In one patient, an initial internal shunt was transformed to a cystoperitoneal shunt. After surgery, all patients experienced relief of symptoms. Reduction of cyst volume occurred in 11 patients. The patients were tested for brain asymmetries related to language and verbal memory before and after operation, with a dichotic listening technique with simultaneous presentation of different auditory stimuli to the two ears. In the preoperative memory test, the patients showed impaired total recall compared with healthy control subjects, and recall from the right ear was significantly impaired. The patients also performed poorly in a forced attention task consisting of dichotic presentations of consonant-vowel syllables. In addition to clinical improvement, the surgical procedures led to improvements in both dichotic perception and memory. Overall memory performance was enhanced, mainly because of improved recall from the right ear. This normalisation of memory function was found as early as four hours after the operation. The results indicate that arachnoid cysts in the left temporal fossa may impair cognitive function, that neuropsychological tests are necessary to disclose these impairments, and that cognitive improvement occurs after surgery.
\end{abstract}

(F Neurol Neurosurg Psychiatry 1995;59:293-298)

Key words: arachnoid cysts; language; memory.

Lesions occupying intracranial space, such as haematomas, tumours, or cysts may impair brain function. The underlying mechanisms for this disturbance in the case of rapidly expanding haematomas are well understood, and may be related to changes in general or local tissue perfusion. The reduced cerebral perfusion may be due to raised intracranial pressure, complicated by the presence of oedema, itself a mass lesion, changes in cerebrovascular reactivity, or the diffusion of possible toxic products. The mechanisms underlying neurological deficit in such indolent lesions as arachnoid cysts are far from clear. The intracranial pressure is seldom raised enough for reduced tissue perfusion to be the mechanism underlying loss of function. Because clinical improvement may occur after decompression, it would seem likely that the neurological deficit is related to processes which, although impairing neuronal function, do not necessarily result in cell death.

Arachnoid cysts are thought to be due to a maldevelopment of the cerebral meninges. ${ }^{12}$ This may be present at birth or develop soon after. ${ }^{34}$ After an initial growth in early life, most cysts are thought to remain stable over many years, ${ }^{5}$ having reached a permanent size which may well be substantial. Very few cysts have been reported to disappear spontaneously. ${ }^{6-10}$ Moreover, some seem to continue to grow in adult life; although slowly. ${ }^{11}$

The symptoms associated with arachnoid cysts vary according to the site of the lesion and the neural structures surrounding them. In adults, subjective complaints such as headache and dizziness are common. Major neurological symptoms such as motor or sensory deficits, epilepsy, or language problems may also occur, although they are often slight and tend to develop late in life. The lack of dramatic symptoms, even in patients with large arachnoid cysts, probably reflects the brain's ability to compensate for the presence of a slowly growing or stable expansion.

If arachnoid cysts cause disabling symptoms such as a paresis, dysphasia, epilepsy, or severe headache, or they are complicated by a subdural haematoma, there is a clear indication for surgery. On the other hand, if the symptoms are less dramatic, some authors favour conservative treatment. ${ }^{12-17}$ The relative paucity of symptoms despite massive displacement of brain tissue is taken to indicate satisfactory cerebral compensation. ${ }^{18}$ Moreover, some earlier series reported a significant mortality and morbidity after surgery for these "uncomplicated" cases, and this has also prompted caution. ${ }^{13}{ }^{19-22}$

In common with any other intracranial expansive lesion, arachnoid cysts have the potential to impaire cognitive function. Such impairments may well contribute to the patient's incapacity, but are not easily shown by a clinical neurological examination. To date, subtle cognitive impairments associated with intracranial expansions have received much less attention than the more dramatic and easily recognisable overt neurological 
symptoms and findings. Indeed, there are few reports dealing with cognitive functions in patients with arachnoid cysts. Lang et $a l^{23}$ found a reduced ability to learn and memorise hemisphere specific material in patients with middle fossa cysts, whereas other reports have failed to show cognitive impairments in such patients. ${ }^{1524}$

If cognitive deficits could be shown in patients with otherwise "silent" cysts, and if cyst surgery improves these functions, the indications for surgery may be expanded considerably, and the decision to operate would be taken on a broader basis.

Nearly half of the arachnoid cysts occur in the middle cranial fossa, ${ }^{2}$ with a pronounced preference for the left side. ${ }^{25}$ Most cysts therefore affect the speech dominant hemisphere. For this reason, two tests were chosen for the present study, based on the dichotic listening technique. ${ }^{26}$ These tests are sensitive to differences in hemispheric functions and in particular probe left hemispheric verbal functions. Dichotic listening procedures have previously proved sensitive in reflecting changes in processing of verbal stimuli produced by discrete electrical stimulation of the ventrolateral thalamus ${ }^{27} 28$ and in recovery of language functions after a stroke. ${ }^{29}$ Moreover, a memory version of the dichotic listening test was used by Christianson et $a l^{30}$ when investigating hemispheric specific memory impairments in two cases of localised head trauma.

\section{Patients and methods \\ PATIENTS}

Thirteen consecutive patients ( $11 \mathrm{men}$, two women) were included in the study as the experimental group. To keep the material as homogenous as possible, only patients with cysts in the left temporal fossa were included. Another inclusion criterion was clinical improvement after surgery (experienced by all the patients). Handedness was defined with the help of a Norwegian translation of the questionnaire developed by Raczkowski et al. ${ }^{31}$ The patient had to indicate 13 of the 15 items performed with the right hand to be classified as right handed. Two of the patients ( 1 and 7) indicated preference for the left hand; the others were classified as right handers. Hearing acuity was determined by a Tegnér screening audiometer. All patients had normal hearing, and patients with an imbalance in hearing between the ears of more than $5 \mathrm{~dB}$ were not included in the study.

All patients were referred to surgery because of pronounced clinical symptoms. Headache was the most prominent, present in all the patients before operation. One patient (11) had had epilepsy for many years, and two patients had recently developed epileptic seizures (5 and 6). One of these (5) also showed a slight right sided hemiparesis although without dysphasia. Another patient (3) had had a transient, slight right sided hemiparesis four months before the operation. None of the remaining patients had experienced any gross neurological disturbance. In one patient (4) with a recent history of head trauma, a subchronic subdural effusion/ haematoma overlying the cyst was drained separately before the preoperative dichotic listening tests and the shunt operation that eventually drained the cyst.

\section{CONTROL GROUPS}

Seven patients with arachnoid cysts of the right temporal fossa served as a control group for the preoperative scores. As only three of these patients were operated on statistical analyses of the effects of decompressive surgery in patients with right sided cysts could not be performed.

Healthy subjects (age $<50$ years) also served as normal controls in both the dichotic memory $(n=32)$, and the dichotic listening $(\mathrm{n}=52)$ tests.

\section{DICHOTIC LISTENING STIMULUS MATERIALS AND TEST PROCEDURES}

We used a modified version of the dichotic memory test described by Christianson et al. ${ }^{30}$ Three different series of 10 nouns were presented two seconds apart to the right or the left ear, with the same nouns played simultaneously backwards to the other ear. The patients were asked to recall all items remembered for 30 seconds after each series of 10 words. The results were averaged over the three series, the maximum score for each ear thus being 10. To control for possible learning effects due to repeated presentations of the dichotic memory test, three parallel versions of the test were used. There might, however, still be some learning of the test situation itself. To control for this possibility, seven patients with left sided cysts and three with a similar cyst on the right side were tested (preoperatively) more than once.

Preoperatively, each patient was tested at least once. Only the score from the first preoperative test was used as the preoperative score in the statistical analyses. For seven of the patients operated on under local anaesthesia, the immediate postoperative condition was so good that it allowed systematic collection of data two or three times during the first postoperative week. The first of these postoperative tests took place four hours after the operation, except in patient 1 who was tested after 24 hours. The immediate postoperative condition did not allow a similar systematic testing during the first postoperative week in the patients operated on with a full craniotomy under general anaesthesia. All the patients were tested when returning to the hospital for the routine follow up three to six months postoperatively.

In the dichotic memory test, the 32 control subjects showed equal recalls from the right and left ears.

The overall memory performance (mean of the recalls from the right ear and the left ear) were also calculated for analyses between the experimental group and the two control groups, and between the results before and after operation in the experimental group.

The patients were also examined with a 
dichotic test emphasising verbal perception, described in detail elsewhere. ${ }^{26}$ In this dichotic listening test, the stimuli consisted of the six stop consonants $b, d, g, p, t, k$, all paired with the vowel $a$ to form six consonant-vowel (CV) syllables ( $b a, d a, g a$, etc). The syllables were paired with each other for all possible combinations, thus yielding 36 dichotic pairs. The dichotic tape consisted of three lists of 36 dichotic randomly ordered $\mathrm{CV}$ pairs each. Each syllable had a duration of $320 \mathrm{~ms}$, and synchronisation of onset between channels was performed for both the consonant and vowel segment onsets. The interstimulus interval was $4 \pm 1 \mathrm{~s}$.

In the dichotic listening test, the patients were tested in three different conditions. In the non-forced (NF) condition they were simply instructed to report freely all the syllables they heard. In the forced right (FR) or forced left (FL) conditions, they were instructed to attend to and report only what they heard in the right or left ear. ${ }^{32}$

The stimuli for the dichotic listening and memory tests were played to the patient from a minicassette player through plug in type earphones. The intensity of the output from the earphones were on average $75 \mathrm{dBA}$ (repeated measurements) when tested with a sound level meter.

To facilitate comparisons with other studies, the raw scores were transformed to percentage scores. To evaluate any change in ear advantage for both the dichotic listening and the dichotic memory tests, a laterality index was calculated according to the formula:

$$
(\mathrm{RE}-\mathrm{LE}) /(\mathrm{RE}+\mathrm{LE}) \times 100
$$

where RE and LE reflect the recalls from the right and the left ears respectively. This yields a positive score for right ear advantage (REA), a negative score for a left ear advantage (LEA), and zero for no ear advantage (NEA). The laterality index compensates for individual differences in overall performance.

Table 1 Data from 13 patients treated, with clinical improvement, for arachnoid cysts in the left temporal fossa showing the size (type) of the cyst, the type of operation, and preoperative and postoperative scores for correct recall from right (RE) and left (LE) ear in the dichotic memory task

\begin{tabular}{|c|c|c|c|c|}
\hline Patient No & Cyst type & Operation & $\begin{array}{l}\text { Preoperative } \\
R E \quad L E\end{array}$ & $\begin{array}{l}\text { Follow up } \\
R E \quad L E\end{array}$ \\
\hline $\begin{array}{l}1 \\
2 \\
3 \\
4 \\
5 \dagger \\
6 \\
7 \\
8 \\
9 \\
10 \\
11 \\
12 \\
13\end{array}$ & $\begin{array}{l}\text { II-III } \\
\text { II } \\
\text { III } \\
\text { III } \\
\text { II-III } \\
\text { I-II } \\
\text { II-III } \\
\text { III } \\
\text { II } \\
\text { II-III } \\
\text { II } \\
\text { I-II } \\
\text { II }\end{array}$ & $\begin{array}{l}\text { Shunt } \\
\text { Shunt } \\
\text { Shunt } \\
\text { Shunt } \\
\text { Shunt } \\
\text { Shunt } \\
\text { Craniotomy } \\
\text { Shunt } \\
\text { Craniotomy } \\
\text { Craniotomy } \\
\text { Craniotomy } \\
\text { Shunt } \\
\text { Craniotomy }\end{array}$ & $\begin{array}{l}3.0<5.0(4.0) \\
3.0<4.0(3.5) \\
4.3<5.3(4.8) \\
4.3<6.3(5.3) \\
1.3<4.7(3.0) \\
3.5>3.2(3.3) \\
7.7>6.3(7.0) \\
1.3<4.7(3.0) \\
1.7<3.7(2.7) \\
4.0<5.0(4.5) \\
5.0<4.3(4.7) \\
4.0<4.3(4 \cdot 2) \\
2.3<3.3(2.8)\end{array}$ & $\begin{array}{l}5.0>4.3(4.7) \\
4.0-4.0(4.0) \\
6.0>5.3(5.7) \\
5.0<5.7(5.3) \\
6.0<6.7(6.3) \\
5.0>4.0(4.5) \\
8.7>7.3(8.0) \\
5.7>4.3(5.0) \\
3.3<5.3(4.3) \\
5.7<6.7(6.2) \\
6.3>4.3(5.3) \\
5.7<6.7(6.2) \\
5.3>3.3(4.3)\end{array}$ \\
\hline Total & & & $3 \cdot 5<4 \cdot 6(4 \cdot 1)$ & $5.5>5.2(5.4)$ \\
\hline
\end{tabular}

Scores in parenthesis indicate the overall performance as the means of right and left ear recalls. *According to the classification of Galassi et al of middle fossa arachnoid cysts, type I is the smallest, situated entirely within the sylvian fissure. Type III is the largest cyst type, also extending over the cerebral convexity. ${ }^{39}$

tLost to three to six months follow up because he developed a left subdural chronic haematoma two months after the shunt operation. The data listed under follow up for this patient are therefore those obtained in a test two days after the evacuation of this haematoma through a burr hole.
SURGERY

Five of the patients underwent a craniotomy with fenestration of the cyst to the basal cisterns during general anaesthesia. The remaining eight patients were operated on with an internal shunt procedure under local anaesthesia. This procedure and the clinical results will be reported in detail elsewhere. ${ }^{33}$ Briefly, a small craniectomy was made and the wall of the cyst and the adjacent cortex were exposed. The cyst membrane was opened at the edge, and an angled Holter ventricular catheter inserted into the cavity. The distal end of the catheter was placed in the subdural space overlying normal cortex, thus allowing the cyst fluid to be drained into the subdural compartment. This procedure reduced or eliminated the symptoms in seven patients, and proved sufficient as the only treatment in six. In one patient (5) with a large cyst, the internal shunt operation caused a near complete collapse of the cyst, followed by considerable clinical improvement. This collapse was associated with the development of a subdural haematoma before the planned follow up. The follow up data presented for this patient were therefore obtained after removal of this haematoma. In the last patient (3), the operation induced a contralateral, expanding subdural effusion. The shunt was therefore transformed to a conventional cystoperitoneal shunt, resulting in an immediate improvement. The postoperative scores reported for this patient are therefore those obtained after the shunt revision.

All the patients experienced a postoperative clinical improvement, and CT at the three to six months follow up showed reduction of the cyst volumes in all the patients except two (3 and 6).

\section{Results}

MEMORY

Table 1 shows the performance in the dichotic memory test. Ten of the 13 patients showed better recall from the left ear (LE) than from the right ear (RE) in the preoperative dichotic memory test, with a significant left ear advantage (LEA) for the group as a whole (RE 3.5 v LE 4.6, $\mathrm{t}(12)=2.84, \mathrm{P}<$ $0 \cdot 01)$. These preoperative scores differed significantly from the scores obtained in the normal control group ( $n=32$; RE $5.9 v$ LE 5.9), both with respect to overall memory performance (4.1 $v 5.9$ for the patient and control groups respectively, $t(43)=3.65, p<0.01$ ), and the presence of an LEA in the patient group $(t(43)=2.01, P<0.01)$.

The preoperative memory ear advantage scores in the 13 patients with left sided cysts (table 1) were also significantly different from those of the seven control patients with cysts in the right middle fossa, who as a group exhibited an REA (RE $3.9 v$ LE 3.5; $\mathrm{t}(18)=$ $2.69, \mathrm{P}<0.05$ ).

At follow up, the preoperative LEA of the experimental group disappeared for all comparisons, with an improvement of the right ear performance in all the patients (table 1). The 
Table 2 Dichotic memory data (raw scores) from seven local anaesthesia patients where the immediate postoperative condition was so good that it allowed early (four hours and three to seven days) postoperative testing

\begin{tabular}{|c|c|c|c|c|}
\hline Patient No & $\begin{array}{l}\text { Preoperative } \\
R E \quad L E\end{array}$ & $\begin{array}{l}4 \text { hours } \\
R E \quad L E\end{array}$ & $\begin{array}{l}3-7 \text { days } \\
R E \quad L E\end{array}$ & $\begin{array}{l}\text { Follow up } \\
R E \quad L E\end{array}$ \\
\hline $\begin{array}{r}1 \\
2 \\
3 \\
4 \\
5 \\
6 \\
12\end{array}$ & $\begin{array}{l}3 \cdot 0<5 \cdot 0(4 \cdot 0) \\
3 \cdot 0<4 \cdot 0(3 \cdot 5) \\
4 \cdot 3<5.3(4 \cdot 8) \\
4 \cdot 3<6.3(5 \cdot 3) \\
1 \cdot 3<4 \cdot 7(3.0) \\
3 \cdot 5>3 \cdot 2(3.3) \\
4 \cdot 0<4.3(4 \cdot 2)\end{array}$ & $\begin{array}{l}3.0<4.0(3.5)^{\star} \\
3.3<3.7(3.5) \\
5.7>4.3(5.0) \\
5.0<5.3(5 \cdot 2) \\
5.7>4.7(5 \cdot 2) \\
4.3>3.0(3.7) \\
5.7>3.3(4.5)\end{array}$ & 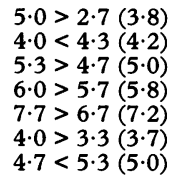 & 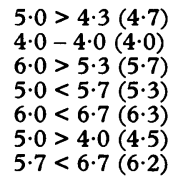 \\
\hline Total & $3 \cdot 3<4 \cdot 7(4 \cdot 0)$ & $4 \cdot 7>4.0(4.4)$ & $5 \cdot 2>4 \cdot 7(4 \cdot 9)$ & $5 \cdot 2-5 \cdot 2(5 \cdot 2)$ \\
\hline
\end{tabular}

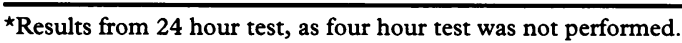

difference between the laterality index before and after operation was significant $(-11 \cdot 1 v$ $2 \cdot 8, \mathrm{t}(12)=3 \cdot 28, \mathrm{P}<0 \cdot 05)$.

The patients also improved their overall memory performance postoperatively. At the time of follow up, 12 patients had improved their overall performance, whereas it remained unchanged in the last patient. The group average increased from a preoperative score of $4 \cdot 1$ to $5 \cdot 4$ at follow up (table 1 ). The increase in overall performance was significant $(\mathrm{t}(12)=5.54, \mathrm{P}<0.001)$

The seven patients operated on under local anaesthesia showed rapid improvement during the first postoperative week (table 2). There was a significant improvement of the overall memory score from the preoperative test to the postoperative tests $(F(3,18)=$ $4 \cdot 70, P<0.05)$. Further tests (NewmanKeuls) showed that the significant improvement occurred three to seven days after the operation, and at the follow up control (all $\mathrm{P}<0.05$ ).

There was also a rapid postoperative change in the ear advantage in these patients (table 2). The ear advantage in the memory test changed significantly from a preoperative LEA to an REA during the first two postoperative tests (at four hours and seven days) and a no ear advantage (NEA) at follow up were also significant $(F(3,18)=4.83, P<0.05)$. The Newman-Keuls test showed that the changes were significant for all three comparisons (all $P<0.05$ ). These comparisons were performed on laterality index scores as described. In the 10 patients who were tested preoperatively more than once to control for possible learning effects of repeated testing,

Table 3 Individual dichotic memory scores from the postoperative period after the first, unsuccessful, operation in patient 3

\begin{tabular}{|c|c|c|c|}
\hline \multirow[b]{2}{*}{$\begin{array}{l}\text { Preoperative } \\
R E \quad L E\end{array}$} & \multicolumn{3}{|l|}{ Postoperative } \\
\hline & $\begin{array}{l}4 \text { hours } \\
R E \quad L E\end{array}$ & $\begin{array}{l}24 \text { hours } \\
R E \quad L E\end{array}$ & $\begin{array}{l}\text { Day } 6 \\
R E\end{array}$ \\
\hline $4.3<5.3(4.8)$ & $5 \cdot 7>4.3(5.0)$ & $5 \cdot 7>4.7(5 \cdot 2)$ & $3.3<4.0(3.7)$ \\
\hline
\end{tabular}

Note the rapid normalisation of the response pattern and overall performance (in parentheses) that was evident four hours after the operation. The right ear superiority was also present the next day but disappeared on the sixth postoperative day, indicating the shunt failure that was verified later. The immediate postoperative normalisation possibly reflects a temporarily lowered intracystic pressure after the first operation. there was no significant difference between the results from the first and last tests. This was true both for overall memory performance and ear advantage, and also when patients with cysts on the left and the right side were analysed separately.

The dichotic memory test seemed sensitive not only in disclosing preoperative impairments and postoperative improvements, but also treatment failures. In one patient (3), the shunt operation caused an immediate and pronounced improvement in the dichotic memory test performance. During the first postoperative week, it became clear that this improvement was only temporary, as the initial postoperative REA disappeared at the sixth day (table 3 ). At this time there was no other indication of the shunt failure that weeks later necessitated a shunt revision.

\section{PERCEPTION}

The patients were also tested with the dichotic listening test, emphasising laterality for perception of dichotically presented CV syllables. Table 4 summarises the results. Preoperatively, the group displayed a weak and statistically non-significant LEA during the NF test. In normal controls, a significant REA is seen. ${ }^{26}$ The ear advantages varied considerably between the patients. The results in the NF test differed, however, significantly from those of the normal control group $(n=52)$ for the laterality index scores as well as total number of correctly perceived syllables. $t$ Tests showed both the comparisons to be significant $(t(63)=8.79, P<0.001$ and $t(63)=6.39, P<0.001$ respectively).

The preoperative performance during the FR and FL tests were below normal on both sides. ${ }^{32}$ As a group, the patients were able to direct their attention to and increase their responses from the right and the left ear. Their scores were significantly below those of the normal control group, however, with respect to both the laterality indices and the absolute number of correctly perceived syllables $(t(63)=4 \cdot 27$ and $3 \cdot 16$ for the FR and FL conditions respectively; $\mathrm{P}<0.01$ ).

The cyst operations did not change the non-forced dichotic listening pattern in any significant way, and the distinct REA seen in normal subjects was not seen in the postoperative controls either. In the forced attention tests, the operation caused significant changes. In the FR test at follow up, the patients displayed the expected superiority (advantage) from the right ear (to which attention was directed). The scores from that ear were significantly higher than the scores obtained in the preoperative FR and the postoperative NF tests, and the scores were no longer different from those of the normal control group in the similar (FR) situation. The same general response pattern (with an LEA) was seen in the FL condition. Comparing the postoperative laterality indices with the preoperative indices for each of the two forced listening conditions (FR, FL), showed significant changes $(t(12)=2.15, P<0.05$, and $1 \cdot 83, \mathrm{P}<0.05$, respectively). 
Table 4 Data (\% correct reports) from the dichotic listening test, collected in three different test situations

\begin{tabular}{|c|c|c|c|c|c|c|}
\hline \multirow[b]{2}{*}{ Patient No } & \multicolumn{2}{|c|}{ Non-forced (NF) } & \multicolumn{2}{|c|}{ Forced right (FR) } & \multicolumn{2}{|c|}{ Forced left (FL) } \\
\hline & $\begin{array}{l}\text { Preoperative } \\
R E \quad L E\end{array}$ & $\begin{array}{l}\text { Follow up } \\
R E \quad L E\end{array}$ & $\begin{array}{l}\text { Preoperative } \\
R E \quad L E\end{array}$ & $\begin{array}{l}\text { Follow up } \\
R E \quad L E\end{array}$ & $\begin{array}{l}\text { Preoperative } \\
R E \quad L E\end{array}$ & $\begin{array}{l}\text { Follow up } \\
R E \quad L E\end{array}$ \\
\hline $\begin{array}{r}1 \\
2 \\
3 \\
4 \\
5 \\
6 \\
7 \\
8 \\
9 \\
10 \\
11 \\
12 \\
13\end{array}$ & $\begin{array}{l}47>43 \\
57>40 \\
43>50 \\
27<73 \\
53>40 \\
63>33 \\
43-43 \\
23<40 \\
23<30 \\
30<40 \\
30>23 \\
20<37 \\
50-50\end{array}$ & $\begin{array}{l}47>40 \\
33<67 \\
47<50 \\
47-47 \\
50>47 \\
47>40 \\
40<53 \\
47>37 \\
17-17 \\
43>37 \\
30-30 \\
57>23 \\
40<60\end{array}$ & $\begin{array}{l}63>17 \\
67>23 \\
40<47 \\
47>27 \\
37<53 \\
67>13 \\
73>17 \\
27<47 \\
30-30 \\
50>20 \\
47>17 \\
20<37 \\
50>40\end{array}$ & $\begin{array}{l}63>23 \\
70>30 \\
60>37 \\
67>7 \\
57>33 \\
60>23 \\
80>7 \\
43-43 \\
27>23 \\
60>20 \\
47>27 \\
63>20 \\
67>30\end{array}$ & $\begin{array}{l}50>40 \\
27<60 \\
60>40 \\
13<47 \\
40<57 \\
60>40 \\
17<73 \\
27<43 \\
13<33 \\
23<43 \\
23<33 \\
27<33 \\
10<67\end{array}$ & $\begin{aligned} 40 & <47 \\
10 & <90 \\
50 & >43 \\
27 & <60 \\
23 & <70 \\
30 & <57 \\
7 & <60 \\
43 & <47 \\
13 & <37 \\
27 & <57 \\
33 & <37 \\
30 & <57 \\
17 & <83\end{aligned}$ \\
\hline $\begin{array}{l}\text { Total } \\
\text { Controls } \\
(n=52)\end{array}$ & $\begin{array}{l}39<42 \\
53>41\end{array}$ & $42-42$ & $\begin{array}{l}47>30 \\
62>26\end{array}$ & $59>25$ & $\begin{array}{l}30<47 \\
30<56\end{array}$ & $27<57$ \\
\hline
\end{tabular}

In the non-forced condition, the patients were instructed to report freely the syllables heard in either ear. In the forced right or forced left conditions, they were instructed to pay attention to, and report only the syllables presented to the right or the left ear. Note the improvement in the forced conditions.

\section{Discussion}

In the present study, dichotic listening techniques emphasising memory and perception showed lateralised cognitive deficits in patients with arachnoid cysts of the left middle fossa. The impairments affected memory and the ability to direct attention in an auditory, perceptual task, and disappeared after decompressive cyst surgery. Normalisation of the memory functions occurred within hours or days.

\section{DICHOTIC LISTENING AND MEMORY}

These non-invasive techniques have previously proved sensitive in reflecting discrete changes in language functions produced by electrical stimulation of the brain, ${ }^{2728}$ in patients with localised brain damage, ${ }^{3034-38}$ and in recovery of language functions after a stroke. $^{29}$

The clinical and behavioural implications of the cognitive impairments reported here remain uncertain, but they may mirror deficits that are of importance to the patient. In this context it is interesting to note that none of our patients had experienced any gross problems with speech or memory; neither were such deficits disclosed by neurological examination before surgery.

The present results thus indicate that lateralised neuropsychological tests may have the potential to disclose subtle, subclinical cognitive impairments in patients with lesions in the region of the left sylvian fissure. Some earlier studies have failed to show cognitive impairment in patients with arachnoid cysts, ${ }^{1524}$ whereas Lang et $a l^{23}$ found learning and memory deficits for hemisphere specific materials in their patients. One reason for the contradictory results may be that the neuropsychological tests used in these studies differed, and that some of them possibly lacked the appropriate specificity for the hemisphere or brain region affected by the cyst. Our tests were chosen specifically to show dysfunction of temporal areas in the left and the right hemispheres. Cognitive functions other than memory and perception may also be impaired in these patients. For lesions with other locations in the left or the right hemisphere, different tests must be selected.

Normal adults have the ability to direct their auditory attention to any of the two sides in the dichotic listening test. ${ }^{32}$ Our patients lacked this ability preoperatively and regained it after surgery, indicating that cerebral structures close to the left sylvian fissure are instrumental in an auditory attention mechanism, and not only important for perception from the contralateral right ear. These findings may well be explained within Kimura's model for dichotic listening. ${ }^{35}$ In her model, auditory information from the left ear reaches the left temporal lobe mainly via the right temporal lobe and the corpus callosum, thus being weakened and delayed compared with the more direct input from the right ear. The lesions in our patients may have disturbed the normal ability to enhance the weakened and delayed information from the ipsilateral left ear, and in some cases also the perception from the contralateral right ear.

\section{ARACHNOID CYSTS AND COGNITIVE IMPAIRMENT}

Arachnoid cysts are space occupying intracranial lesions, and the symptoms they cause are often surprisingly moderate considering their substantial volumes. One reasonable explanation of the stable appearance and relative paucity of symptoms may be that the intracystic and intracranial pressures are only moderately raised, a common finding during operation. The pressure exerted on neighbouring cerebral structures is therefore probably also moderate, although the physical displacement of the same structures may be massive. Whether the neurological and neuropsychological deficits caused by arachnoid cysts are precipitated by an increased tissue pressure or the displacement of brain tissue, or a combination of these or other factors, remain unsolved.

There is every reason to assume that arachnoid cysts in adults have affected the surrounding cerebral structures for many years. It would therefore be a reasonable assumption that the associated brain damage 
and concomitant symptoms might be permanent, and refractory to any form of surgical correction. The rapid restoration of cognitive functions in our patients after decompressive surgery shows that this is not the case. This indicates that middle fossa arachnoid cysts may cause a reversible suppression of neuronal function rather than a permanent destruction of cerebral tissue.

The present results may have implications for future preoperative considerations in patients with arachnoid cysts. The cognitive improvement after decompression in these patients is so important that it may lower the threshold for operative treatment, even in patients with moderate clinical symptoms. Consequently, specific neuropsychological test batteries that tap lateralised functions should be developed for clinical use. Our tests were sensitive to, and therefore suitable for probing asymmetric hemisphere functions related to memory and language. For cysts with other locations (frontal, parietal, or occipital), tests should be added for temporal sequencing, neglect, and visuospatial functions.

We are indebted to Janniche Alvær and Cathrine Hovland for assistance in the collection of data. The research was supported by grants from the Norwegian Medical Research Council (NAVF-RMF) and Nansen-fondet to KW and KH.

1 Starkman SP, Brown TC, Linell EA. Cerebral arachnoid cysts. F Neuropathol Exp Neurol 1958; 17:484-500.

2 Rengachary SS, Watanabe I. Ultrastructure and pathogenesis of intracranial

Neurol 1981;40:61-83.

3 Geissinger JD, Kohler WC, Robinson BW, Davis FM Arachnoid cysts of the middle cranial fossa: surgical considerations. Surg Neurol 1978;10:27-33.

4 Kumagai M, Sakai N, Yamada H, Shinoda J, Nakashima $\mathrm{T}$, Iwama $\mathrm{T}$, Ando $\mathrm{T}$. Postnatal development and enlargement of primary middle cranial fossa arachnoid cyst recognized on repeat CT scans. Child's Nerv Syst 1986;2:211-5.

5 Rengachary SS. Intracranial arachnoid and ependymal cysts. In: Wilkins RH, Rengachary SS, eds. Neurosurgery, Vol III. New York: McGraw-Hill, 2160-72.

6 Beltramello A, Mazza C. Spontaneous disappearance of a large middle fossa arachnoid cyst. Surg Neurol 1985;24: 181-3.

7 Yamanouchi Y, Someda K, Oka N. (1986) Spontaneous disappearance of middle fossa arachnoid cyst after head injury. Child's Nerv Syst 1986;2:40-3.

8 Inoue T, Matsushima T, Tashima S, Fukui M, Hasuo K. Spontaneous disappearance of a middle fossa arachnoid cyst associated with subdural hematoma. Surg Neurol cyst associated with

9 Weber R, Voit T, Lumenta C, Lenard HG. Spontaneous regression of a temporal arachnoid cyst. Child's Nerv Syst 1991;7:414-5.

10 Wester K, Gilhus NE, Hugdahl K, Larsen JL. Spontaneous disappearance of an arachnoid cyst in the middle intracranial fossa. Neurology 1991;41:1524-6.

11 Becker $T$, Wagner $M$, Hofman $E$, Warmuth-Metz $M$, CT volumetric study. Neuroradiology 1991;33:341-5.

12 Mayr U, Aichner F, Bauer G, Mohsenipour I, Pallua A Supratentorial extracerebral cysts of the middle cranial fossa Neurochirurgia (Stuttg) 1982;25:51-6.

13 Cilluffo JM, Onofrio BM, Miller RH. The diagnosis and surgical treatment of intracranial arachnoid cysts. Acta Neurochir 1983;67:215-29.

14 Gandy SE, Heier LA. Clinical and magnetic resonance feature of primary in

J, Dietz $\mathrm{H}$ Clinical and neuKunz U, Ruckert N, Tagert J, Dietz ropsychological results after operative and conservative treatment of arachnoidal cysts of the perisylvian region. Acta Neurochir 1988; Suppl 42:216-20.

16 Dei-Anang K, Voth D. Cerebral arachnoid cyst: a lesion of the child's brain. Neurosurg Rev 1989:12:59-62.

17 Robertson SJ, Wolpert SM, Runge VM. MR imaging of middle fossa arachnoid cysts: temporal lobe agenesis syndrome revisited. AfNR Am $\mathcal{F}$ Neuroradiol 1989;10: 1007-10.

18 Holst S. Congenital intracranial arachnoidal cysts. Case reports and discussion of the pathogenesis. $\mathcal{f}$ Oslo City Hosp 1965;15:113-20.

19 Aicardi J, Bauman F. Supratentorial extracerebral cysts in infants and children. $\mathcal{F}$ Neurol Neurosurg Psychiatry 1975; 38:57-68.

20 Choux M, Raybaud C, Pinsard N, Hassoun J, Gambarelli G. Intracranial supratentorial cysts in children excluding G. Intracranial supratentorial cysts in children excluding

21 Lodrini S, Lasio G, Fornari M, Miglivacca F. Treatment of supratentorial primary arachnoid cysts. Acta Neurochir 1985;76:105-10.

22 Marinov M, Undjian S, Wetzka P. An evaluation of the surgical treatment of intracranial arachnoid cysts in children. Child's Nerv Syst 1989;5:177-83.

23 Lang W, Lang M, Kornhuber A, Gallwitz A, Kriebel J. Neuropsychological and neuroendocrinological disturbances associated with extracerebral cysts of the anterio and middle cranial fossa. Eur Arch Psychiatr Neurol Sci 1985;235:38-41.

24 Gallassi R, Ciardulli C, Ferrara R, Lorusso S, Galassi E, Lugaresi E. Asymptomatic large cyst of the middle cranial fossa. A clinical and neuropsychological study. Eur Neurol 1985;24:140-4.

25 Wester K. Gender distribution and sidedness of middle fossa arachnoid cysts: a review of cases diagnosed with computed imaging. Neurosurgery 1992;31:940-44.

26 Hugdahl K, ed. Handbook of dichotic listening: theory, methods and research. New York: Wiley and Sons 1988.

27 Ojemann GA. Enhancement of memory with human ventrolateral thalamic stimulation. Effect evident on dichotic listening task. Appl Neurophysiol 1985;48:212-5.

28 Hugdahl K, Wester K, Asbjernsen A. The role of the left and right thalamus in language asymmetry: dichotic listening in Parkinson patients undergoing stereotactic thalamotomy. Brain Lang 1990;39:1-13.

29 Hugdahl K, Wester K, Asbjørnsen A. Dichotic listening in an aphasic male patient after a hemorrhage in the left fronto-parietal region. Intern 7 Neuroscience 1990;54: fronto-parie.

30 Christianson SÅ Nilsson LG, Silfvenius $H$. Initial memory deficits and subsequent recovery in two cases of memory deficits and subsequent recovery in two

31 Raczkowsky D, Kalat JW, Nebes R. Reliability and validity of some handedness questionnaire items. Neuropsychologia 1974;12:43-7.

32 Hugdahl K, Andersson L. The "forced-attention paradigm" in dichotic listening to CV-syllables: a comparison between adults and children. Cortex 1986;22 417-32.

33 Wester K. Arachnoid cysts in adults. Experience with internal shunts to the subdural compartment. Surg Neurol 1995 (in press).

34 Kimura D. Some effects of temporal lobe damage on auditory perception. Can $\mathcal{f}$ Psychol 1961;15:156-65.

35 Kimura D. Functional asymmetry of the brain in dichotic listening. Cortex 1967;3:163-78.

36 Eslinger PJ, Damasio H. Anatomical correlates of paradoxic ear extinction. In: Hugdahl $\mathrm{K}$, ed. Handbook paradoxic ear extinction. In: Hugdahl $\mathrm{K}$, ed. Handbook of dichotic listening: theory, methods

37 Hugdahl K, Wester K. Dichotic listening studies of hemispheric asymmetry in brain damaged patients. Intern $\mathcal{f}$
, Wester $\mathrm{K}$. Dichotic listening studies of hemiNeuroscience 1992;63:17-29.

38 Hugdahl K, Wester K, Asbjernsen A. Auditory neglect after right frontal lobe and right pulvinar thalamic lesions. Brain Lang 1991;41:465-73.

39 Galassi E, Tognetti F, Gaist G, Fagioli L, Frank F, Frank G. CT scan and metrizamide CT cisternography in arachnoid cysts of the middle cranial fossa: classification and pathophysiological aspects. Surg Neurol 1982;17: 363-9. 